\title{
A CLINICOPATHOLOGICAL STUDY OF VARIOUS LESIONS ENCOUNTERED IN CYSTOSCOPIC BLADDER BIOPSIES
}

\author{
Nilima Khochikar1, Vaibhav P. Mane², D. G. Mote, V. R. Pawar', Sushant Mohite, ${ }^{5}$ Vanisha Dhaka ${ }^{6}$ \\ ${ }_{13}^{\text {rd }}$ Year MBBS Student, Bharati Vidyapeeth Medical College and Hospital, Sangli. \\ ${ }^{2}$ Associate Professor, Department of Pathology, Bharati Vidyapeeth Medical College and Hospital, Sangli. \\ 3 Professor, Department of Surgery, Bharati Vidyapeeth Medical College and Hospital, Sangli. \\ 4 Professor, Department of Pathology, Bharati Vidyapeeth Medical College and Hospital, Sangli. \\ ${ }^{5}$ Senior Resident, Department of Pathology, Bharati Vidyapeeth Medical College and Hospital, Sangli. \\ ${ }^{6}$ Senior Resident, Department of Pathology, Bharati Vidyapeeth Medical College and Hospital, Sangli.
}

\section{ABSTRACT}

\section{BACKGROUND}

In clinical practice tumours of the bladder are one of the most common urological lesions observed and it is the $7^{\text {th }}$ most common cancer worldwide. Urinary bladder malignancies accounts for $3.2 \%$ of all cancers worldwide and males are commonly affected than females. Non-neoplastic lesions like chronic non-specific cystitis is most commonly seen and is important source of clinical signs and symptoms. Aim of the present study was to analyse the histopathological findings of different lesions in cystoscopic biopsies and to study the frequency of different pathological lesions with respect to age, sex, clinical symptoms, etc.

Aims and Objectives - 1. To study the distribution of various lesions on histopathology. 2. To study the age, sex, clinical features in bladder lesions.

\section{MATERIALS AND METHODS}

A 5-year retrospective study was carried out in Department of Pathology. The slides were retrieved and diagnoses were confirmed. The necessary clinical data was collected from the record sections.

\section{RESULTS}

The present study was conducted over a period of 5 years, during which a total of 25 cystoscopic biopsies were studied. In males, malignancy is common as compared to females. The maximum incidence was in $6^{\text {th }}$ decade. The most common presenting feature was haematuria. In our study, incidence of invasive urothelial carcinoma - high-grade was more. During this period, total cases were 25 , among which $40 \%$ were non-neoplastic lesions and $60 \%$ were neoplastic lesions.

\section{CONCLUSION}

Malignant tumours are common in bladder and are a major cause of morbidity and mortality. In non-neoplastic lesions, cystitis constitutes an important source of clinical signs and symptoms. Histopathological study of cystoscopic biopsy helps in early detection of tumour and its management.

\section{KEYWORDS}

Urothelial Lesions, Bladder Carcinoma, Non-Neoplastic Lesions, Neoplastic Lesions.

HOW TO CITE THIS ARTICLE: Khochikar N, Mane VP, Mote DG, et al. A clinicopathological study of various lesions encountered in cystoscopic bladder biopsies. J. Evolution Med. Dent. Sci. 2016;5(87):6466-6468, DOI: 10.14260/Jemds/2016/1462

\section{BACKGROUND}

Significant morbidity and mortality is seen in malignant and non-malignant lesions of urinary bladder. $(1,2,3)$ Certain biologic and clinical challenges are present in spite of newer techniques for diagnosis and treatment. Cystoscopy is the primary investigation for patients of bladder tumours, which allows a direct visualisation of the bladder mucosa and biopsies of the suspected lesions. $(4,5)$ Urinary bladder cancer is the sixth most common cancer in the world. After prostate

Financial or Other, Competing Interest: None.

Submission 17-09-2016, Peer Review 19-10-2016,

Acceptance 25-10-2016, Published 28-10-2016.

Corresponding Author:

Dr. Vaibhav P. Mane,

Flat No. 1, Shri Ramshailya Apartment,

Neminathnagar, Near Ganpati Temple,

Vishrambag, Sangli-416415,

Maharashtra.

E-mail: vaishnailab1060@gmail.com

DOI: $10.14260 /$ jemds/2016/1462 cancers, it is next common malignancy in genitourinary tract. $(4,6)$

In malignant neoplasms of urinary bladder, urothelial carcinoma is the commonest tumour. Most cases present in patients over the age of 50 years with increased incidence in men than women.(7) The most common sign is gross and microscopic haematuria. $(1,2,5,6)$ Cystoscopy is the primary diagnostic tool.

The prevalence of urinary bladder lesions is higher in developed than in the developing countries with the risk factors being environmental factors, industrial exposure to arylamines, chronic analgesic use, chronic cigarette smoking and Schistosoma haematobium infestation. $(8,9,10)$

Cystitis is the commonest non-neoplastic lesion. These diseases are more disabling than lethal.(11) The present study aimed to study the histopathological features of various lesions of the urinary bladder through cystoscopic biopsy over a period of five years in a teaching hospital. 


\section{Aims and Objectives}

1. To determine the clinicopathological incidence of various urinary bladder lesions on cystoscopic biopsies that presented to tertiary hospital.

2. To categorise them as per the age groups and clinical symptoms.

3. To see the incidence of various non-neoplastic and neoplastic lesions.

4. To compare them with other studies.

\section{MATERIALS AND METHODS}

This is a study conducted in the Department of Pathology of tertiary teaching hospital over a period of 5 years. All patients who visited Urology Department for cystoscopic biopsy are included. The biopsies taken by Urologist were sent to the Department of Pathology for processing. Biopsies were fixed in $10 \%$ formalin. Five micron sections were cut and the prepared slides were stained with Haematoxylin and Eosin $(\mathrm{H}$ and E) stain.

Microscopic features were studied and relevant findings were noted. Patient's details were obtained from patient's report file. The tumours were graded as per the World Health Organisation (WHO) classification of the urinary tract and classified into infiltrating urothelial carcinoma, non-invasive urothelial neoplasia (low grade and high grade) and glandular neoplasm.

Data was analysed and tabulated for evaluation. The present study was approved by the Institute of Ethical Committee.

\section{Collection of Data}

This was a 5-year study conducted in the Department of Pathology. All patients who visited the Surgery/Urology outpatient department and presenting with urinary complaints like haematuria, dysuria, etc. were included in the study. Cystoscopic bladder biopsies were performed.

\section{Inclusion Criteria}

All cystoscopic biopsies taken from the urinary bladder and renal pelvis, received in Department of Pathology, were considered for the study.

\section{Exclusion Criteria}

Cystoscopic bladder biopsies, which are not properly fixed are excluded from the study.

\section{Statistical Analysis}

Microsoft Office 2007 was used to generate tables. Results of the study are based on descriptive statistics and presented as mean and percentage.

\section{RESULTS}

A total of 25 cystoscopic biopsies were taken in a study period. Out of these cases, $18(72 \%)$ were male and $07(28 \%)$ were female with a male-to-female ratio of 2.6:1. Malignancy was more commonly seen in male patients; 25 urinary bladder biopsies were studied which included patients of all age groups, ranging from 12-72 years. The maximum number of cases were seen in between $4^{\text {th }}$ to $6^{\text {th }}$ decades of life with maximum cases seen in 41-60 years of age.

The least number of cases were seen in the extremes of age groups. Among the 25 cases, 10 were non-neoplastic and 15 were neoplastic lesions. Of the 10 non-neoplastic lesions, there were 07 cases of non-specific cystitis, two cases of exostrophy showing metaplastic changes and one case of Cystitis glandularis.

Among the neoplastic lesions, most of the cases were in the $5^{\text {th }}$ and $6^{\text {th }}$ decade of life and more than half of them were males. Of the 15 neoplastic lesions, 13 cases were papillary urothelial carcinomas and 02 cases were squamous cell carcinomas. Of the 13 papillary urothelial carcinomas 04 cases were low-grade papillary urothelial carcinomas, 06 were highgrade urothelial carcinomas and 03 cases were high-grade urothelial carcinoma showing squamous differentiation. Of the 04 low-grade papillary urothelial neoplasms, 02 were noninvasive and 02 were invasive carcinomas.

\begin{tabular}{|c|c|c|c|c|}
\hline Age in Yrs. & Male & Female & Total & $\mathbf{\%}$ \\
\hline$<20$ & 01 & 01 & 02 & 08 \\
\hline $21-30$ & 01 & 01 & 02 & 08 \\
\hline $31-40$ & 01 & 01 & 02 & 08 \\
\hline $41-50$ & 04 & 01 & 05 & 20 \\
\hline $51-60$ & 05 & 02 & 07 & 28 \\
\hline $61-70$ & 04 & 01 & 05 & 20 \\
\hline $71-80$ & 02 & 00 & 02 & 08 \\
\hline Total & 18 & $\mathbf{0 7}$ & $\mathbf{2 5}$ & $\mathbf{1 0 0}$ \\
\hline \multicolumn{6}{|l}{ Table 1. Age Wise Distribution of Cases } \\
\hline
\end{tabular}

\begin{tabular}{|c|c|c|}
\hline Chief Complaints & No. of Cases & Percentage \\
\hline Haematuria & 18 & 72 \\
\hline Abdominal Pain & 04 & 16 \\
\hline Urgency & 03 & 12 \\
\hline \multicolumn{2}{|c|}{ Table 2. Chief Complaints } \\
\hline
\end{tabular}

\begin{tabular}{|c|c|c|c|}
\hline Sl. No. & Type of Lesion & No. of Patients & Percentage \\
\hline 1 & Non-neoplastic & 10 & 40 \\
\hline 2 & Neoplastic & 15 & 60 \\
\hline \multicolumn{2}{|c|}{ Total } & $\mathbf{2 5}$ & $\mathbf{1 0 0}$ \\
\hline \multicolumn{2}{|c|}{ Table 3. Clinical Presentation of Patients } \\
\hline
\end{tabular}

\begin{tabular}{|c|c|c|}
\hline Diagnosis & No. of Cases & $\%$ \\
\hline Chronic non-specific cystitis & 07 & 70 \\
\hline Metaplastic changes & 02 & 20 \\
\hline Cystitis glandularis & 01 & 10 \\
\hline Total & 10 & 100 \\
\hline
\end{tabular}

\begin{tabular}{|c|c|c|}
\hline Diagnosis & $\begin{array}{c}\text { No. of } \\
\text { Cases }\end{array}$ & $\mathbf{\%}$ \\
\hline LGPUN & 04 & 26.64 \\
\hline HGPUN & 06 & 39.96 \\
\hline $\begin{array}{c}\text { HGPUN with squamous } \\
\text { differentiation }\end{array}$ & 03 & 19.98 \\
\hline SCC & 02 & 13.32 \\
\hline Total & $\mathbf{1 5}$ & $\mathbf{1 0 0}$ \\
\hline \multicolumn{2}{|c|}{ Table 5. Distribution of Neoplastic Lesions } \\
\hline
\end{tabular}

\section{DISCUSSION}

Cystoscopy can be used as a primary investigation for bladder lesions and cystoscopic biopsies are useful for planning the treatment.

In the present study, $72 \%$ were male and $18 \%$ were female with a male-to-female ratio of 2.6:1. Similar finding was seen in several studies of cystoscopic biopsy. Bladder carcinoma is more common in elderly males. The maximum number of cases were seen in between $4^{\text {th }}$ to $6^{\text {th }}$ decades of life.(1,2,12) In our study, Brunn's nest is seen in 39\% cases of cystitis and 9\% cases of urothelial neoplasm. Srikousthubha et al(1) had shown 
the association of Brunn's nest with cystitis in his study. Urothelial tumour was the commonest type of malignant lesion. Detrusor muscle was not seen in $28 \%$ cases. Therefore, the invasion cannot be assessed. In his study, Laishram et al(5) found muscle invasion in $42.1 \%$ cases.(5) Our study showed $25 \%$ cases of invasive urothelial carcinoma. Hence, inclusion of detrusor muscle in the cystoscopic biopsy is very important.

Special mention should be given to PUNLMP, papillary urothelial neoplasm of low malignant potential. On histopathology it shows only increase in thickness of epithelium, but the cells does not exhibit cytologic atypia; feature also seen in papilloma.(13,14,15) During cystoscopy, PUNLMP lesions are less than $2 \mathrm{~cm}$ with papillary projections. Histopathologically, they show more than seven layer thick urothelium with cells without any cytological atypia.(13,16,17)

On the contrary, low-grade papillary urothelial carcinoma will show thickened urothelium with papillary fronds with minimum cytological atypia. $(3,4,6,18)$ Very rarely these lowgrade tumour would also recur if there was an evidence of invasion. $(1,2,4,5)$

Urothelial neoplasm which show papillary fronds of urothelium, which shows a significantly disordered architectural and cytologic pattern with moderate cytologic atypia. $(6,7,8)$ It contains cells that are dyscohesive with large hyperchromatic nuclei, high degrees of anaplasia and atypical mitotic figures. Architectural disarray with loss of polarity is a characteristic feature of these tumours.

In urothelial carcinoma different histopathological features exhibiting squamous, glandular, micropapillary, sarcomatoid, small cell, plasmacytoid and undifferentiated feature are also frequently noted. These different microscopic differentiation should be mentioned in the report, as it has prognostic significance. $(1,2,8,9)$

In urinary bladder, chronic nonspecific cystitis is the most common non-neoplastic lesion seen. It has other variants like xanthogranulomatous types, Granulomatous cystitis, metaplastic changes and malakoplakia ${ }^{(2,3)}$ are also noted.

7 cases of chronic nonspecific cystitis were noted in the present study, which correlates with the study done by Sri Kousthubha et al(1) where $84 \%$ of the non-neoplastic lesions were inflammatory lesions.

Urinary bladder lesions, non-neoplastic and neoplastic are collectively responsible for significant morbidity and mortality throughout the world. Cystoscopy can be used as a primary diagnostic tool for the patients who are suspected of having bladder tumours, which allows a direct visualisation of the bladder mucosa and biopsies of the suspected lesions.

\section{CONCLUSION}

In our study, most of the non-neoplastic lesions were of urothelial lesion with most of the cases are of chronic nonspecific cystitis. Histopathological study of cystoscopic biopsy helps in early detection of tumour. Grading of tumours with note on muscle invasion would be helpful for treatment of patient.

\section{ACKNOWLEDGEMENT}

The authors are thankful to the Department of Urology, Technicians of Histopathology Section of Pathology Department, BVDUMC \& H, Sangli, for their help and cooperation.

\section{REFERENCES}

1. Srikousthubha, Sukesh, Raghuveer CV, et al. Profile of lesions in cystoscopic bladder biopsies. A histopathological study. J Clin Diagn Res 2013;7(8):1609-12.

2. Stepan A, Simionescu C, Margaritescu C, et al. Histopathological study of the urothelial bladder carcinomas. Current Health Science Journal 2013;39(3):147-50.

3. Stepan A, Florescu A, Mitrut A, et al. Histological variants of urothelial bladder carcinoma. Current health Sciences Journal 2010;36(3):139-42.

4. Al-Samawi AS, Aulaqi SM. Urinary bladder cancer in Yemen. Oman Med J 2013;28(5):337-40.

5. Laishram RS, Kipgen P, Laishram S, et al. Urothelial tumors of the urinary bladder in Manipur: ahistopathological perspective. Asia Pacific Journal of Cancer Prevention 2012;13(6):2477-9.

6. Vaidya S, Lakhey M, Hirachand S, et al. Urothelial tumors ofthe urinary bladder: a histopathological study of cystoscopic biopsies. J Nepal Med Assoc 2013;52(191):475-8.

7. Kumar UM, Yelikar BR. Spectrum of lesions in cystoscopic bladder biopsies- a histopathological study. Al Ameen J Med Sci 2012;5(2):132-6.

8. Islam AHMT, Mostafa SN, Rahman M, et al. Role ofultrasound in the evaluation of urinary bladder neoplasm withhistopathological correlation. Journal of Teachers Association TAJ 2008;21(2):155-9.

9. Murphy DM, Zincke H, Furlow WL. Management of highgrade transitional cell cancer of the upper urinary tract. J Urol 1981;125(1):25-9.

10. Ahmed Z, Muzaffer S, Khan M, et al. Transitional cell carcinomas of the urinary bladder. A histopathological study. J Pak Med Assoc 2002;52(9):396-8.

11. Ranadive NU, Deodhar KP, Bapat SD. Usefulness of urinary bladder biopsies. study of 98 cases. J Postgrad Med 1983;29(1):10-4.

12. Gupta P, Jain M, Kapoor R, et al. Impact of age and gender on the clinicopathological characteristics of bladder cancer. Indian J Urol 2009;25(2):207-10.

13. Rauniyar SK, Agrawal A, Shah A. A study of cystoscopicbiopsies in Kathmandu valley. J Nepal Med Assoc 2001;40(140):181- 5.

14. Kapur P, Lotan Y, King E, et al. Primary adenocarcinoma of the urinary bladder: value of cell cycle biomarkers. Am J Clin Pathol 2011;135(6):822-30.

15. Pindiga UH, Bama ML, Abdullahi M. Carcinoma of theurinary bladder in Maiduguri, Nigeria: a retrospective histopathological study of 100 cases. Highland Medical Research Journal 2004;2(1):41-44.

16. Felix AS, Soliman AS, Khaled H, et al. The changing patterns of bladder cancer in Egypt over the past 26 years. Cancer Causes \& Control 2008;19(4):421-9.

17. Eble JN, Sauter G, Epstein JI, et al. eds. World Health Organization of tumors. Tumors of the urinary system and male genital organs. Lyon: IARC Press 2004.

18. Biswas RR, Mangal S, Guha D, et al. An epidemiological study of cases of urothelial carcinoma of urinary bladder in a tertiary care centre. Journal of Krishna Institute of Medical Sciences University 2013;2(1):82-8. 